\title{
ENSINO DE DIDÁTICA E O PAPEL DOS PROFESSORES FORMADORES NO CONTEXTO DAS PRÁTICAS PEDAGÓGICAS: DO QUE ESTAMOS FALANDO?
}

\author{
TEACHING DIDACTICS AND THE ROLE OF TEACHER \\ EDUCATORS IN THE CONTEXT OF PEDAGOGICAL \\ PRACTICES: WHAT ARE WE TALKING ABOUT?
}

\section{ENSEÑANZA DE DIDÁCTICA Y EL PAPEL DE LOS PROFESORES FORMADORES EN EL CONTEXTO DE LAS PRÁCTICAS PEDAGÓGICAS: ¿DE QUÉ ESTAMOS HABLANDO?}

Osmar Hélio Alves Araújo ${ }^{1}$ ${ }^{1}$ Universidade Federal do Sul e Sudeste do Pará (UNIFESSPA), Marabá/PA-Brasil

Resumo Este artigo discute o papel dos professores formadores no ensino de Didática, como ciência do ensino; um saber/um ramo do conhecimento, tendo como referência suas práticas pedagógicas. A pesquisa de natureza teórica parte do pressuposto de que as práticas pedagógicas desses professores são instrumentos chave para o desenvolvimento profissional e para a formação pedagógica dos estudantes dos cursos de licenciatura. A partir da questão central - qual é o papel dos professores formadores no ensino de Didática nos cursos de licenciatura, tendo como referência suas práticas pedagógicas? -, argumenta-se que o ensino de Didática e o conhecimento da e sobre a Didática, como compromisso de todos os professores formadores, merece atenção especial de modo que efetivamente a formação pedagógica dos estudantes seja trabalhada com qualidade.

Palavras-chave: Prática pedagógica; Professor formador; Didática; Pedagogia; ForMAÇÃO DOCENTE. 
Abstract This article discusses the role of teacher educators in the teaching of Didactics as a teaching science; a knowledge/branch of knowledge, with its pedagogical practices used as reference. This research, of a theoretical nature, is based on the assumption that the pedagogical practices of these teachers are key instruments for the professional development and pedagogical training of undergraduate students. From the central question - what is the role of teacher trainers in teaching didactics in undergraduate courses in the context of pedagogical practices? - what is the role of teacher educators in teaching Didactics in licentiate courses, with their pedagogical practices used as reference? - it is argued that the teaching of Didactics and the understanding of and on Didactics, as commitments of all teacher educators, deserve special attention, so that the pedagogical training of students is effectively cultivated with quality.

Keywords: Pedagogical practice; Teacher trainer; Didactics; Teacher training.

Resumen Este artículo discute el papel de los profesores formadores en la enseñanza de Didáctica como ciencia de la instrucción; un saber/un ramo del conocimiento, teniendo como referencia sus prácticas pedagógicas. La investigación, de naturaleza teórica, parte del presupuesto de que las prácticas pedagógicas de estos profesores son instrumentos clave para el desarrollo profesional y para la formación pedagógica de los estudiantes de las carreras de licenciatura. A partir de la cuestión central - ¿cuál es el papel de los profesores formadores en la enseñanza de la Didáctica en las carreras de licenciatura, teniendo como referencia sus prácticas pedagógicas? - se argumenta que la enseñanza de Didáctica y el conocimiento de y sobre la Didáctica, como compromiso de todos los profesores formadores, merecen atención especial de modo que efectivamente la formación pedagógica de los estudiantes sea trabajada con calidad.

Palabras clave: Prácticas Pedagógicas; Profesor formador; Didáctica; Formación doCENTE.

\section{INTRODUÇÃo}

As práticas pedagógicas dos professores formadores, quando vazias das teorias pedagógica e não comprometidas com a formação pedagógica dos professores, dizem da não qualidade da educação brasileira e do seu não efetivo compromisso com a formação e a atuação profissional dos futuros professores. A Didática é elemento intrínseco à formação e ao exercício profissional dos professores. Não importa a disciplina, "[...] a Didática aparece como elemento fundamental para o desenvolvimento do trabalho docente" (RIOS, 2015, p. 649). Os professores, por isso, precisam de elementos teórico-metodológicos, didático-pedagógicos que vão além do domínio do conhecimento de determinada área da ciência.

A ação de ensinar sem a Didática fica comprometida e, muitas vezes, não leva à aprendizagem. A razão de ser da Didática, em contrapartida, são os processos de ensino e aprendizagem. Assim como não é possível exercer a docência sem a ação de ensinar, não é 
possível ser professor formador sem a Didática. Nessa perspectiva, pergunto: qual é o papel dos professores formadores no ensino de Didática ${ }^{1}$ nos cursos de licenciatura, ${ }^{2}$ tendo como referência suas práticas pedagógicas? As práticas pedagógicas dos professores formadores têm tido um peso na aprendizagem da profissão docente pelos estudantes, e, por isso, na sua futura atuação profissional e nas experiências, de agora, nos cursos de licenciatura (D’AVILA, 2007; CRUZ; MAGALHÃES, 2017).

Há aqueles professores formadores que são para os estudantes exemplos fortes de como "não fazer" ou de como "não ser" (D’AVILA, 2007). Para alguns estudantes, o professor formador ideal é aquele que, acima de tudo, tem domínio do conteúdo teórico-prático e competência didática e pedagógica, articuladas a atributos, como: ser paciente, tolerante, amigo, flexível e afetuoso (GABRIELLI; PELÁ, 2004). Em síntese, o papel do professor é reconhecido pelos estudantes e sua prática pedagógica observada como parâmetro de definição para a construção da sua futura prática profissional (CRUZ; MAGALHÃES, 2017). São essas constatações, entre outras, que tenho observado a partir da experiência docente no Ensino Superior, que me instigaram a escrever este artigo.

Esta reflexão é, portanto, orientada pelo reconhecimento da importância das práticas pedagógicas dos professores formadores para o ensino de Didática nos cursos de licenciatura. Entendo, por isso, que é fundamental que seja posto em evidência nas práticas pedagógicas desses professores a Didática crítica-fundamental (CANDAU, 1983); a Didática como uma reflexão crítica sobre os processos de ensino e aprendizagem. Ou seja, que os estudantes, futuros professores, reconheçam nas práticas pedagógicas dos seus professores um contexto didático e pedagógico de articulação teoria-prática; conhecimento científico e pedagógico, assim como práticas de problematização e de novas proposições para o ensino; e, em especial, contexto de articulação com os saberes pedagógicos. ${ }^{3}$

O foco deste estudo recaiu, portanto, sobre as práticas pedagógicas de todos os professores formadores dos cursos de licenciatura. Parafraseando Nóvoa (2017b), penso que é com todos os professores formadores, muitas vezes, no contexto dos cursos de licenciatura, que os estudantes aprendem a sentir, a agir, a apreender a profissão docente e a construir a sua posição como profissional e, sobretudo, a sentir-se como professor.

1 Ao tratar do ensino de Didática não estou fazendo referência, necessariamente, às disciplinas que tratam de questões gerais de Didática; das didáticas específicas das áreas das ciências, ou, ainda, das práticas de ensino e estágios. Estou, na verdade, argumentando ser necessário serem as práticas pedagógicas dos professores formadores uma afirmação da Didática; das suas especificidades e compromisso com os fenômenos ensino e aprendizagem.

2 Os cursos de formação inicial para os profissionais do magistério para a educação básica no Brasil, em nível superior, compreendem: I - cursos de graduação de licenciatura; [...]. Os cursos de graduação de licenciatura são organizados em áreas especializadas, por componente curricular ou por campo de conhecimento e/ou interdisciplinar (BRASIL, 2015).

3 Adoto, neste texto, o conceito de saber pedagógico desenvolvido por Franco (2016). A autora diz que “[...] saber pedagógico não é o conteúdo da pedagogia, mas aquilo que nos permite agir pedagogicamente. Digo o mesmo em relação à prática: esta não é um fazer, nem um saber fazer; a prática é a possibilidade de mobilização crítica de um saber-fazer" (FRANCO, 2016b, p. 62). 
Para efeitos desta discussão, entendo práticas pedagógicas como práxis e, por isso, "como uma ação consciente e participativa, que emerge da multidimensionalidade que cerca o ato educativo" (FRANCO, 2016a, p. 536). Temos argumentado serem as práticas pedagógicas práxis, um agir pedagógico transformador e que, a partir do seu compromisso sociopolítico, procura (cor)responder aos desafios dos tempos atuais, e transformar a sociedade de modo a abrir possibilidades para a existência de vida plena para todos (ARAÚJO; RODRIGUES, 2018).

Este texto discute, então, o papel dos professores formadores no ensino de Didática, nos cursos de licenciatura, tendo como referência suas práticas pedagógicas. A pesquisa de natureza teórica parte do pressuposto de que as práticas pedagógicas dos professores formadores são instrumentos chave para o desenvolvimento profissional e a formação pedagógica dos estudantes dos cursos de licenciatura. Entretanto, essa questão exige, necessariamente, que os professores formadores possuam conhecimentos, competências e habilidades didático-pedagógicas que fortaleçam o ensino e a apreensão da Didática como ciência do ensino.

Nesta discussão, trabalho com a hipótese de que as práticas pedagógicas dos professores formadores, de um modo ou de outro, dialogam com a Pedagogia e a Didática e, por isso, devem ser subsídio para o desenvolvimento profissional e para a formação pedagógica dos estudantes dos cursos de licenciatura. Sublinho, portanto, que o ensino de Didática, como compromisso de todos os professores formadores, merece atenção especial de modo que efetivamente a formação pedagógica dos estudantes seja trabalhada com qualidade.

Inicialmente, argumento serem a Pedagogia e a Didática pontos transversais na formação dos professores para, em seguida, problematizar o papel dos professores formadores no ensino de Didática nos cursos de licenciatura, tendo como referência suas práticas pedagógicas.

\section{Pedagogia e didática como eixo transversal na formaÇão dos Profes- SORES}

Podemos encontrar duas perspectivas quando se trata da definição de Didática. A encontramos como um saber, um campo do conhecimento; uma ciência que tem um objeto próprio - os processos de ensino e aprendizagem. Assim como a definição de Didática como uma disciplina da grade curricular dos cursos de formação docente (RIOS, 2014). A Didática, como diz, ainda, Rio (2015), quer como ciência ou disciplina constituinte da formação dos professores, deve fornecer aporte teórico-prático para uma ação docente competente.

Quando articulada à Pedagogia e à Didática, assim como às demais ciências que auxiliam os processos de ensino e aprendizagem, há sempre a possibilidade da prática docente se constituir como um contexto eminentemente social, político e pedagógico e superar possíveis dificuldades, desafios, e atingir seu objetivo fundamental: possibilitar a produção do conhecimento pelos sujeitos (ARAÚJO, 2018). Pois, a Didática, com foco notadamente 
nos processos de ensino e aprendizagem, é, sobretudo, a construção de conhecimentos que permitem a existência de um processo educativo verdadeiramente pleno de sentido.

A Didática se volta essencialmente para a docência/a ação de ensinar, na busca constante da compreensão, problematização e de novas proposições para o ensino, e focando, acima de tudo, a mediação docente de modo indissociável da intencionalidade político-pedagógica. Logo, segundo Cruz, Marcel (2014); Franco, Pimenta (2016), a Didática se elabora e estrutura no ensino, produzindo conhecimento sobre e para ele, e, notadamente, na responsabilidade dos professores e na aprendizagem dos alunos.

Tenho argumentado que a Didática, quer como instrumento político, como campo teórico-prático, ou como prática social, deve apontar para novas possibilidades de investigação dos fenômenos de ensino e aprendizagem, com clareza da realidade do contexto social-político brasileiro e, assim, contribuir com os professores diante das contradições e desafios que estão postos à docência na contemporaneidade (ARAÚJO, 2018). Com isso quero enfatizar que, a Didática visa mais do que um processo educativo dissociado dos problemas da realidade brasileira, de uma prática em uma perspectiva de memorização, de repetição de exercícios ou, ainda, do simples acesso e apreensão da cultura geral.

Quanto à Pedagogia, vislumbro-a como prática social e que, como tal, procura organizar, compreender e transformar as práticas sociais educativas que dão sentido e direção às práticas educacionais. Podemos dizer ainda que a Pedagogia, como prática social, oferece/impõe, propõe/indica uma direção de sentido às práticas que ocorrem na sociedade, realçando seu caráter eminentemente político (FRANCO, 2016a). Rios (2014, p. 108) nos ajuda compreender a distinção entre a Pedagogia e a Didática. Segundo a autora, a diferenciação se dá em virtude de a "Pedagogia constituir-se como um esforço de pensar a práxis educativa e os problemas dela decorrente. Como ciência da Educação, volta-se para aquela práxis de maneira específica [...]". Do ponto de vista da autora, a Didática se volta, necessariamente, para o ensino construído na instituição escolar, a partir de sua organização curricular, objetivos, organização de conteúdo, métodos de trabalho e proposição de avaliação do processo.

A ação de ensinar, essência do exercício docente, como já enfatizado, se situa, portanto, no campo da Pedagogia e da Didática. Pois, o fenômeno ensino e aprendizagem, como processo complexo realizado entre os sujeitos professores e alunos, situados em contextos, imbricado nas condições históricas e mediado por múltiplas determinações, exige fundamentos pedagógicos essenciais (FRANCO; PIMENTA, 2016). Situo, por isso, a Pedagogia e a Didática como ponto de convergência das diversas disciplinas dos cursos de licenciatura e como eixo transversal na formação dos professores.

Assim como a Pedagogia, a Didática é um potente campo epistemológico teórico-prático para a formação profissional do professor, de modo a construir saberes próprios para a atuação profissional (MARAFELLI; RODRIGUES; BRANDÃO, 2017).

A Pedagogia e a Didática podem ser consideradas como ponto de articulação, diálogo e convergência entre as diferentes disciplinas dos cursos de licenciatura. Ou seja, toda a ação de ensinar nos cursos de formação de professores, conduzida pelos fundamentos didá- 
ticos e pedagógicos, deve culminar com um trabalho político-pedagógico capaz de formar o trabalhador intelectual e profissional da docência.

Toda a ação de ensinar desvinculada de uma base sólida teórico-metodológica, didático e pedagógica torna o ensino de qualquer disciplina um simples treinamento do fazer ou do pensar (FRANCO; PIMENTA, 2016). A Pedagogia e a Didática, por isso, fazem parte da essência do ser professor, da sua formação e do seu desenvolvimento profissional. Problematizar o exercício docente implica articulá-lo necessariamente às teorias pedagógicas que, de um ou de outro modo, estão presentes na ação de ensinar.

O alicerce da ação de ensinar deve ser, assim, o conhecimento científico e cultural, articulados a uma consciência crítica (NÓVOA, 2017a). A ação de ensinar nos cursos de formação de professores não pode ficar reduzida apenas ao domínio das disciplinas específicas, ${ }^{4}$ das diversas áreas das ciências, em detrimento das teorias pedagógicas, e vice-versa. A ação de ensinar é complexa e abarca, necessariamente, uma dimensão social, pedagógica, cultural, entre outras.

Como nos ensina Rios (2015), o foco das tarefas dos docentes dos cursos de licenciatura é ensinar a ensinar, é preparar os estudantes para a ação de ensinar. Isso implica reconhecermos que a essência dos cursos de licenciatura é a formação docente pedagógica. ${ }^{5}$ Esse reconhecimento exige, necessariamente, o entrecruzamento de diversos saberes que ganham, no espaço da formação, a configuração de saberes pedagógicos. Por essa e outras razões, temos procurado defender a ideia de que a Pedagogia e a Didática são eixos centrais da formação dos professores (ARAÚJO; RODRIGUES; ARAGÃO, 2017; ARAÚJO; RIBEIRO, 2017).

Só a partir da Pedagogia e da Didática, assim como dos demais campos teóricos, como a Filosofia, a Sociologia, a Antropologia, entre outros, a ação de ensinar, nos cursos de licenciatura, poderá ser um espaço de reflexão sobre o fenômeno educativo e, por isso, contexto de formação e de desenvolvimento profissional docente.

A reflexão na e sobre a ação de ensinar não ocorre desvinculada da Pedagogia e da Didática que lhe atribuam sentido e direção. Penso, inclusive, que a dimensão emancipatória da formação dos professores reside, sobretudo, na triangulação entre as práticas pedagógicas dos professores formadores, a Pedagogia e a Didática e a problematização da realidade social-política contemporânea. Nessas condições, como as práticas pedagógicas desses professores dialogam como o contexto social-político contemporâneo? Se não dialogam, não são verdadeiramente práticas pedagógicas. Por isso, como diz Franco (2013), é preciso pensar articulações cada vez mais profundas entre a teoria e a realidade; assim como fazer

4 As disciplinas dos cursos de licenciatura são organizadas em torno dos conteúdos específicos da respectiva área de conhecimento ou interdisciplinares, seus fundamentos e metodologias, bem como conteúdos relacionados aos fundamentos da educação, formação na área de políticas públicas e gestão da educação, seus fundamentos e metodologias (BRASIL, 2015) e há uma identificação, muito costumeira, como disciplinas específicas e pedagógicas.

5 Rios (2015) tem argumentado, e eu concordo, de que não devemos fazer a distinção entre saberes específicos e saberes pedagógicos quando nos referimos às disciplinas que fazem parte do currículo dos cursos de formação de professores. Segundo a autora, esses saberes estão no âmbito de uma formação pedagógica e eles todos podem ser, ali, qualificados como saberes especificamente pedagógicos. 
dialogar a lógica das práticas com a lógica da formação. Essa é uma tarefa que os cursos de formação devem enfrentar e esse é um exercício fundamental da Pedagogia.

A ação de ensinar dos professores formadores é um trabalho político-pedagógico necessário para a discussão, a reflexão e a compreensão, no contexto dos cursos de licenciatura, sobre o ser professor; a formação docente e a pesquisa; o cotidiano escolar; a profissionalidade e a autonomia docente; os elementos intrínsecos aos processos de ensino e aprendizagem, entre outras temáticas. Logo, a Pedagogia e a Didática lhes servem como subsídios crítico-emancipatórios para a construção de um pensamento reflexivo, assim como para a construção de um trabalho pedagógico que propicie aos estudantes aprendizagens reflexivas e críticas acerca da docência. E, ainda, para a existência de um clima de motivação e trabalho colaborativo, potenciando, desse modo, a qualidade da aprendizagem da profissão docente pelos estudantes.

De um ou de outro modo, a Pedagogia e a Didática constituem-se eixos substanciais das práticas pedagógicas dos professores formadores e, por isso, para a multiplicidade de práticas que possam, ao mesmo tempo, formar os futuros professores e provocar transformações no contexto social-político contemporâneo.

A partir das pesquisas que tenho desenvolvido sobre a Pedagogia e a Didática na formação dos professores, ${ }^{6}$ reafirmo serem a Pedagogia e a Didática pontos centrais na formação dos professores e, por isso, subsídios teórico-metodológicos necessários para a construção do conhecimento científico e pedagógico básico do futuro professor.

\section{ENSINO E A APREENSÃo DE DIDÁTICA E SUA RELAÇÃo COM AS PRÁTICAS PEDAGÓ- GICAS DOS PROFESSORES FORMADORES}

Afinal de contas, quando se trata do ensino de Didática: qual o papel dos professores formadores, tendo como referência suas práticas pedagógicas? O que se espera, no contexto dos cursos de licenciatura, sobretudo, são práticas pedagógicas construídas com e para os estudantes. Não necessariamente os professores formadores precisam ser formados em Pedagogia, assim como desenvolver discussões e análises sobre a Pedagogia e a Didática, mas devem sim exercer a docência de modo articulado à reflexão, ao diálogo e à crítica, elementos intrínsecos à Pedagogia e à Didática, como já enfatizado.

$\mathrm{O}$ que se deseja, portanto, é que os professores formadores não negligenciem seu testemunho ético e profissional de construir uma prática consubstanciada em princípios didáticos e pedagógicos capazes de serem contextos concretos da ação de ensinar e que, por consequência, os estudantes percebam a complexidade e a multidimensionalidade que perpassam os fenômenos ensino e aprendizagem.

$\mathrm{O}$ argumento que orienta esta seção é o papel dos professores formadores com a explicitação de práticas pedagógicas como subsídio para o ensino e a apreensão da Didática como ciência do ensino; um saber/um ramo do conhecimento intrínseco à ação de ensinar. Pois, “[...] não apenas os conteúdos, mas também as práticas de formação devem receber

6 Araújo (2016); Araújo e Magalhães (2017); Araújo; Rodrigues e Aragão (2017); Araújo e Rodrigues (2017). 
atenção especial, pois elas são modeladoras de posturas profissionais futuras" (ANDRÉ; ALMEIDA, 2017, p. 204).

Convém reiterar que estou considerando, neste texto, prática pedagógica como um contexto que envolve as circunstâncias da formação, as parcerias e expectativas dos estudantes, e suas perspectivas e expectativas profissionais.

Quero, assim, evidenciar a importância de se considerar que as práticas pedagógicas dos professores formadores devem ser "bons exemplos" e, por isso, referências para a prática profissional dos futuros professores no tocante, sobretudo, aos elementos didáticos e pedagógicos. Como já enfatizado, e como argumentam Cruz e André (2014), esses elementos fundamentam a ação de ensinar e, por isso, devem ser postos em evidência na própria prática dos professores formadores para que os futuros docentes reconheçam sua pertinência e especificidade.

As práticas pedagógicas dos professores formadores constituem, assim, eixos centrais na construção do conhecimento profissional básico do futuro professor, pois esses professores passam a ser exemplo ou modelo, especialmente por não ser possível, muitas vezes, dicotomizar o conhecimento científico e técnico da própria prática do docente (ANDRÉ; ALMEIDA, 2017; CRUZ; MAGALHÃES, 2017).

Estudos (D'AVILA, 2007; VENTURA et al., 2011; CRUZ; MAGALHÃES, 2017) têm evidenciado que as práticas pedagógicas dos professores formadores são observadas pelos estudantes como parâmetros de definição para a sua futura prática profissional. Da mesma forma, os "bons professores" para os estudantes são aqueles que apresentam, sobretudo, competências pedagógicas e científicas articuladas à responsabilidade profissional e compromisso com a formação dos estudantes.

Os estudos de Cruz e Marcel (2014) indicam que os professores que são apontados como referenciais e cujas práticas possuem status de arquétipo de prática para o futuro professor são aqueles que detêm habilidades, como: saber comunicar, saber argumentar, ser dinâmico, organizado, empenhado e pesquisador. São apontados da mesma maneira os docentes que se destacam principalmente pelas metodologias empregadas, a coerência entre o discurso e as práticas, a relação de proximidade com os alunos, além de atributos pessoais - relacionais e/ ou metodológicos - e domínio do conteúdo. Entretanto, Ventura et al. (2011) também sinalizam que no cenário educacional contemporâneo, "o desempenho docente no ensino superior tem-se caracterizado pelo professor especialista no seu domínio de conhecimento, mas que não domina necessariamente a área educacional e pedagógica” (p. 96).

Reitero, por isso, que o exercício docente exige muito mais do que o domínio de determinada área das ciências, posto que a ação de ensinar abarca uma complexidade e multidimensionalidade que passam necessariamente pelo campo social-político, pedagógico e cultural, entre outros. Ou seja, "Não basta saber o conteúdo. É preciso saber ensinar" (CRUZ; MARCEL, 2014, p. 75).

Apesar das inúmeras dificuldades implicadas no exercício docente nos cursos de licenciatura, ${ }^{7}$ julgo que os professores formadores precisam caminhar para um maior pro-

A esse respeito, ver: André; Almeida, 2017. 
tagonismo na formação pedagógica dos estudantes, futuros professores. Isso implica, necessariamente, construir práticas com feições crítico-colaborativas e a partir das quais os estudantes possam construir relações com o saber pedagógico e novas compreensões em relação à ação de ensinar. Trata-se, portanto, da defesa de que os estudantes possam construir uma identidade profissional com base, sobretudo, nas práticas pedagógicas de professores que, comparativamente a outros, se destaquem pela qualidade didático-pedagógica da sua atuação profissional. Cruz e Marcel (2014, p. 79) apontam esses professores referências para os futuros professores como os que:

[...], ensinam valores aos seus aprendizes, ou, ao menos, acrescentam valores já
construídos nas suas trajetórias. Contribuem para construção de uma identida-
de responsável, o que, consequentemente, nos faz afirmar que terão elementos
para propagar os frutos de um ensino responsável politicamente.

Algumas questões surgem como essenciais: "o que se espera do professor formador? [...] quais seriam os saberes e práticas mais adequados para atender às demandas da profissão no atual contexto social?" (ANDRÉ; ALMEIDA, 2017, p. 204). Um professor que sabe qual é o sentido de construir práticas pedagógicas que possuam status de arquétipo de prática para os futuros professores é consciente do significado da sua atuação pedagógica e, por isso, constrói, com e para os estudantes, práticas que articulem a pluralidade de saberes dos diferentes atores da prática educativa (CRUZ; MARCEL, 2014). Isso exige, necessariamente, uma relação que "envolve diálogo horizontal, respeitoso, estimulante e motivador em torno de um conhecimento importante à profissionalização" (CRUZ; MARCEL, 2014, p. 69).

Assim, os professores formadores que sabem do papel das suas práticas pedagógicas na expansão da formação pedagógica dos estudantes configuram-nas em uma perspectiva crítico-colaborativa; estimulam a reflexão, a dúvida, a criatividade e a inovação e, por consequência, essas práticas pedagógicas são base para o agir, o transformar e autoformar-se dos estudantes. Pois, "[...] é da natureza do pedagógico ser a instância de reflexão e de transformação das práticas escolares" (FRANCO, 2016b, p. 64). Esses professores promovem, ainda, o desenvolvimento profissional dos estudantes, já que, "a formação é fundamental para construir a profissionalidade docente, e não só para preparar os professores do ponto de vista técnico, científico ou pedagógico" (NÓVOA, 2017b, p. 1.130). Promover o desenvolvimento profissional dos estudantes implica, em especial, lhes oferecer possibilidades de aprender/ensinar a ensinar; de construir uma posição como profissional em formação à medida que desenvolvem o sentimento de pertença à profissão docente.

Os professores formadores que estão imbuídos da sua responsabilidade, para com a formação pedagógica dos estudantes, vinculam, de um ou de outro modo, as práticas pedagógicas construídas ao contexto das escolas básicas visando, acima de tudo, possibilitar

8 A profissionalidade diz respeito a saberes próprios da profissão docente, englobando saberes disciplinares e saberes pedagógicos (ANDRÉ; ALMEIDA, 2017, p. 206). 
aos estudantes experiências de inserção e construção de saberes a partir do seu futuro e principal campo de atuação. Assim, precisamos assegurar "maior articulação entre essas duas instituições [escola básica e universidades] e atribuir um maior 'protagonismo dos professores em exercício no sistema escolar' na formação profissional de sua categoria" (MARAFELLI; RODRIGUES; BRANDÃO, 2017, p. 996). Os professores formadores e os estudantes se constituem, assim, uma comunidade de aprendizagens numa perspectiva de construção e desenvolvimento da autonomia discente e docente.

Portanto, discutir o ensino de Didática, e sua relação com o papel dos professores formadores, no contexto das práticas pedagógicas, nos cursos de licenciatura, é, como evidenciado, pensar "uma prática que se exerce com finalidade, planejamento, acompanhamento, vigilância crítica, responsabilidade social" (FRANCO, 2016a, p. 541). Essa prática será, por consequência, contexto concreto para a compreensão das dimensões didático e pedagógica da ação de ensinar, e, possivelmente, exemplos de prática para os futuros professores, e exige que os professores formadores e estudantes, em tempo paralelo, sejam sujeitos intelectualmente críticos, pesquisadores e mediadores da ação de ensinar e sujeitos do ato de aprender.

\section{Algumas considerações e perspectivas expostas no teXto}

Busquei evidenciar com esta discussão que as práticas pedagógicas dos professores formadores são instrumentos centrais para a formação pedagógica dos estudantes à medida que esses professores evidenciarem conhecimentos, competências e habilidades didático e pedagógicas como exemplo concreto da Didática na ação de ensinar.

Do exposto, concluo que se espera que os professores formadores, no contexto das práticas pedagógicas: a) possibilitem o entrecruzamento dos diferentes saberes da profissão docente; b) promovam o desenvolvimento profissional dos estudantes; c) fomentem a reflexão, a dúvida, a criatividade, a inovação e a transformação do meio social-político contemporâneo; d) desenvolvam um trabalho de formação articulado ao contexto escolar das redes de ensino básico, e) construam práticas pedagógicas, em uma ótica crítico-colaborativa, que fomentem o protagonismo dos estudantes para a discussão, a reflexão e para o autoformar-se. Por isso, não podemos definir que o ensino e a compreensão de Didática fiquem reservados às disciplinas que tratam de questões gerais ou específicas desse campo do conhecimento. Pois, a Pedagogia e a Didática precisam estar em evidência nas práticas pedagógicas dos professores formadores à medida que são mediadores da ação de ensinar e cumprem o papel fundamental dos cursos de licenciatura: ensinar a ensinar.

\section{REFERÊNCIAS}

ANDRÉ, Marli Eliza Dalmazo Afonso de; ALMEIDA, Patrícia Cristina Albieri de. A profissionalidade do professor formador das licenciaturas. Rev. educ. PUC-Camp., Campinas, 22 (2): 203-219, mai./ago., 2017. Disponível em: $<$ https://doi.org/10.24220/2318-0870v22n2a3640>. Acesso em: 21 ago. 2018. 
ARAÚJO, Osmar Hélio Alves. Contribuições da Pedagogia para a educação pública brasileira no cenário político-social contemporâneo. Currículo sem Fronteiras, v. 18, p. 1.0441.056, 2018. Disponível em: http://www.curriculosemfronteiras.org/vol18iss3articles/ araujo.pdf. Acesso em: 12 jan. 2019.

ARAÚJO, Osmar Hélio Alves. Metáfora do quebra-cabeça?: ensino e pesquisa na formação docente. Revista Querubim, v. 4, p. 29-32, 2016.

ARAÚJO, Osmar Hélio Alves; MAGALHAES, Célia de Jesus Silva. A pesquisa e o Curso de Letras da URCA, Campus Missão Velha (CE), em diálogo. In: Aluízio Lendl; Maria Lucia Pessoa Sampaio; Marcos Nonato de Oliveira (Org.). Pesquisas e ensino de leitura, literatura e língua portuguesa, 1. ed. Curitiba/PR: EDITORA CRV, 2017, v. 1, p. 136-159.

ARAÚJO, Osmar Hélio Alves; RIBEIRO, Luís Távora Furtado. Tecendo relações entre a disciplina de Didática, a Universidade e o Contexto Escolar. Educação \& Linguagem, v. 21, n. 2, jul./dez. 2017. Disponível em: <http://dx.doi.org/10.15603/2176-1043/ el.v20n2p5-14>. Acesso em: 9 ago. 2018.

ARAÚJO, Osmar Hélio Alves; RODRIGUES, Janine Marta Coelho. A formação contínua dos professores e as avaliações externas no contexto educacional brasileiro. Imagens da Educação, v. 8, n. 1, p. 1-13, 2018. Disponível em: https://doi.org/10.4025/imagenseduc. v8i1.40831. Acesso em: 13 jun. 2018.

ARAÚJO, Osmar Hélio Alves; RODRIGUES, Janine Marta Coelho; ARAGÃO, Wilson Honorato. O (des) lugar da pedagogia e da didática na formação dos professores. Revista on line de Política e Gestão Educacional, Araraquara, v. 21, n. 1, p. 215-226, 2017. Disponível em: $<$ http://dx.doi.org/10.22633/rpge.v21.n.1.2017.9534>. Acesso em: 24 mar. 2018.

BRASIL. Ministério da Educação. Conselho Nacional de Educação. Conselho Pleno. Resolução CNE/CP n. 2/2015. Define as diretrizes curriculares nacionais para a formação inicial em nível superior (cursos de licenciatura, cursos de formação pedagógica para graduados e cursos de segunda licenciatura) e para a formação continuada. Brasília, DF: MEC, 2015. Disponível em: <http:// portal.mec.gov.br/cne/arquivos/pdf/>. Acesso em: 5 ago. 2018.

CANDAU, Vera Maria. A didática e a formação de educadores: da exaltação à negação, a busca da relevância. In: CANDAU, Vera Maria (Org.). A didática em questão. Petrópolis: Vozes, 1983, p. 13-24.

CRUZ, Giseli Barreto da; ANDRÉ, Marli Eliza Dalmazo Afonso de. Ensino de Didática: um estudo sobre concepções e práticas de professores formadores. Educação em Revis- 
ta, Belo Horizonte, v. 30, n. 4, p. 181-203, out./dez. 2014. Disponível em: http://dx.doi. org/10.1590/S0102-46982014000400009. Acesso em: 28 jun. 2018.

CRUZ, Giseli Barreto da; MAGALHÃES, Priscila Andrade. O ensino de didática e a atuação do professor formador na visão de licenciandos de educação artística. Educ. Pesqui., São Paulo, v. 43, n. 2, p. 483-498, abr./jun., 2017. Disponível em: http://dx.doi.org/10.1590/

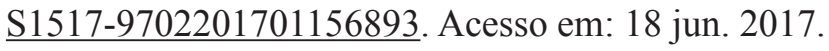

CRUZ, Giseli Barreto da; MARCEL, Jules. A Didática de professores referenciais e suas contribuições para a formação docente. Est. Aval. Educ., São Paulo, v. 25, n. 57, p. 56-82,

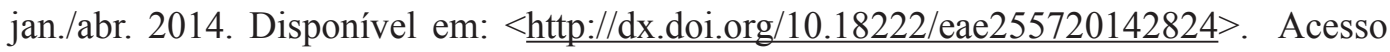
em: 21 ago. 2018.

D’ÁVILA, Cristina Maria. Universidade e formação de professores: qual o peso da formação inicial sobre a construção da identidade profissional docente? In: NASCIMENTO, Antônio Dias; HETKOWSKI, Tânia Maria (Orgs.). Memória e formação de professores. Salvador: EDUFBA, 2007, p. 219-240.

FRANCO, Maria Amélia Santoro. Didática: uma esperança para as dificuldades pedagógicas do Ensino superior? Práxis Educacional, v. 9, n. 15, 2013. Disponível em: http:// periodicos.uesb.br/index.php/praxis/article/view/1947. Acesso em: 4 jul. 2018.

FRANCO, Maria Amélia Santoro. Prática pedagógica e docência: um olhar a partir da epistemologia do conceito. Rev. Bras. Estud. Pedagog [on-line]. 2016a, v. 97, n. 247, p. 534-551. Disponível em: http://dx.doi.org/10.1590/s2176-6681/288236353 . Acesso em: 21 ago. 2018.

FRANCO, Maria Amélia Santoro. Relações do docente-bacharel do ensino superior com o saber didático-pedagógico: dissonâncias e rupturas entre saberes e práticas. Em Aberto, Brasília, v. 29, n. 97, p. 61-72, set./dez. 2016b. Disponível em: < http://dx.doi. org/10.24109/2176-6673.emaberto.29i97.\%25p > . Acesso em: 21 ago. 2018.

FRANCO, Maria Amélia Santoro; PIMENTA, Selma Garrido. Didática multidimensional: por uma sistematização conceitual. Educ. Soc. [on-line], 2016, v. 37, n. 135, p. 539553. Disponível em: http://dx.doi.org/10.1590/ES0101-73302016136048. Acesso em: 22 ago. 2018.

GABRIELLI, Joyce Maria Worschech; PELÁ, Nilza Teresa Rotter. O professor real e o ideal na visão de um grupo de graduandos de enfermagem. Rev Esc Enferm USP, 2004; 38 (2): 168-74. Disponível em: http://www.revistas.usp.br/reeusp/article/view/41393/44972. Acesso em: 21 ago. 2018. 
MARAFELLI, Cecilia Maria; RODRIGUES, Priscila Andrade Magalhães; BRANDÃO, Zaia. A formação profissional dos professores: um velho problema sob outro ângulo. Cadernos de Pesquisa, v. 47 n. 165, p. 982-997, jul./set. 2017. Disponível em: http://publicacoes.fcc.org.br/ojs/index.php/cp/article/view/4293. Acesso em: 21 ago. 2018.

NÓVOA, António. Firmar a posição como professor, afirmar a profissão docente. Cadernos de Pesquisa, v. 47, n. 166, p. 1.106-1.133, out./dez. 2017b. Disponível em: http:// dx.doi.org/10.1590/198053144843. Acesso em: 18 ago. 2018.

NÓVOA, António. "Se fosse brasileiro, estaria indignado com a situação da educação." Carta Capital, 28 de março de 2017a. Disponível em: http://www.cartaeducacao.com. br/reportagens/se-fosse-brasileiro-estaria-indignado-com-a-situacao-da-educacao/. Acesso em: 21 ago. 2018.

RIOS, Terezinha Azerêdo. Ampliar o diálogo de saberes para a docência. In: FRANCO, Maria Amélia Santoro; PIMENTA, Selma Garrido (Orgs.). DIDÁTICA: EMBATES CONTEMPORÂNEOS, 3. ed. São Paulo: Edições Loyola, 2014, p. 101-130.

RIOS, Terezinha Azerêdo. É possível formar professores sem a Didática? In: LIMA, Maria Socorro Lucena et al. (Org.). Didática e prática de ensino: diálogos sobre Escola, formação de professores e sociedade, 1. ed. Fortaleza: Universidade Estadual do Ceará, 2015, v. 4, p. 643-653.

VENTURA, Maria Clara Amado Apóstolo et al. O "bom professor" - opinião dos estudantes. Revista de Enfermagem Referência - III, n. 5, 2011. Disponível em: http://dx.doi. org/10.5902/198464442357. Acesso em: 4 ago. 2018.

\section{DADOS Do AUTOR}

\section{Osmar Hélio Alves Araújo}

Doutor em educação pela Universidade Federal da Paraíba. Paraíba/PB-Brasil. Professor Universidade Federal do Sul e Sudeste do Pará. Marabá/PA-Brasil. osmarhelio@hotmail. com.

Submetido em: 1-9-2018

Aceito em: 20-2-2019 